\title{
Synthesis of Thermally Stable and Highly Active Bimetallic Au-Ag Nanoparticles on Inert Supports
}

\author{
Xiaoyan Liu, ${ }^{\dagger, \ddagger}$ Aiqin Wang, ${ }^{\dagger}$ Xiaofeng Yang, ${ }^{\dagger \neq, \S}$ Tao Zhang, ${ }^{*},{ }^{\dagger}$ Chung-Yuan Mou,, \\ Dang-Sheng $\mathrm{Su},{ }^{\perp}$ and $\mathrm{Jun}_{\mathrm{Li}}{ }^{\S}$ \\ State Key Laboratory of Catalysis, Dalian Institute of Chemical Physics, Chinese Academy of Sciences, \\ Zhongshan Road 457, Dalian 116023, P. R. China, Graduate University of the Chinese Academy of \\ Sciences, Beijing 100049, P. R. China, Department of Chemistry, Tsinghua University, Beijing 100084, P. \\ R. China, Department of Chemistry, National Taiwan University, Taipei 106, Taiwan, and Fritz-Haber \\ Institute of the Max Planck Society, Berlin D-14195, Germany
}

Received October 11, 2008. Revised Manuscript Received November 20, 2008

\begin{abstract}
A general two-step approach has been developed for the synthesis of very small and sintering-resistant bimetallic gold-silver nanoparticles on inert supports including commercial silica and alumina. In this approach, gold particles were formed in the first step on amino-functionalized silica or alumina support. Our density functional theory (DFT) calculations on selected model clusters show that the surface atoms of the gold particles formed in the first step carry slightly negative charges, which facilitates the subsequent $\mathrm{Ag}^{+}$adsorption on the gold particle surface. Upon $\mathrm{Ag}^{+}$adsorption and reduction by $\mathrm{NaBH}_{4}$ in the second step, specific nanoparticles with gold-silver alloy core and a silver nanoshell have been formed, as confirmed by our ultraviolet-visible spectroscopy (UV-vis), high-resolution transmission electron microscopy (HRTEM), and X-ray photoelectron spectroscopy (XPS) characterizations. Such particles have been found to be highly thermally stable, and their sizes remain substantially unchanged $(\sim 3 \mathrm{~nm})$ even upon calcination in air at $500{ }^{\circ} \mathrm{C}$. After the final reduction treatment in $\mathrm{H}_{2}$, a randomly distributed alloy composed of gold and silver is formed, and the resultant $\mathrm{Au}-\mathrm{Ag}$ alloy particles are highly catalytically active for $\mathrm{CO}$ oxidation, even superior to $\mathrm{Au} / \mathrm{TiO}_{2}$. The role of $\mathrm{Ag}$ in stabilizing the particles has been discussed.
\end{abstract}

\section{Introduction}

Supported gold nanoparticles have attracted intensive research interest in heterogeneous catalysis and fuel-cell electrocatalysis in the past two decades because of their exceptionally high activities for low-temperature $\mathrm{CO}$ oxidation ${ }^{1-4}$ and distinguished selectivities in a variety of redox reactions. ${ }^{5-8}$ These unique features are very different from the traditional platinum group metals. One of the most important features of gold catalysis is the striking sizedependence. As bulk gold is highly noble, reactivity of goldbased catalysts is critically dependent on the particle size; only those particles with sizes below $5 \mathrm{~nm}$ show high

* Corresponding author. Fax: 86-411-84691570. Tel: 86-411-84379015. E-mail: taozhang@dicp.ac.cn.

Chinese Academy of Sciences.

* Graduate University of the Chinese Academy of Sciences.

\$ Tsinghua University.

"National Taiwan University.

${ }^{\perp}$ Fritz-Haber Institute of the Max Planck Society.

(1) Haruta, M. Catal. Today 1997, 36, 153.

(2) Schubert, M. M.; Hackenberg, S.; van Veen, A. C.; Muhler, M.; Plzak, V.; Behm, R. J. J. Catal. 2001, 197, 113.

(3) Kung, H. H.; Kung, M. C.; Costello, C. K. J. Catal. 2003, 216, 425.

(4) Comotti, M.; Li, W. C.; Spliethoff, B.; Schüth, F. J. Am. Chem. Soc. 2006, 128, 917.

(5) Grisel, R. J. H.; Nieuwenhuys, B. E. J. Catal. 2001, 199, 48.

(6) Hughes, M. D.; Xu, Y. J.; Jenkins, P.; McMorn, P.; Landon, P.; Enache, D. I.; Carley, A. F.; Attard, G. A.; Hutchings, G. J.; King, F.; Stitt, E. H.; Johnston, P.; Griffin, K.; Kiely, C. J. Nature 2005, 437, 1132.

(7) González-Arellano, C.; Corma, A.; Iglesias, M.; Sánchez, F. J. Catal. 2006, 238, 497.

(8) Wang, X. K.; Wang, A. Q.; Wang, X. D.; Yang, X. F.; Zhang, T. Gold Bull. 2007, 40, 52. reactivities..$^{9-11}$ Preparation of small-sized gold-based nanopartciles on various supports is therefore highly desirable for catalysis. Typically, such small particles are obtained on reducible supports $\left(\mathrm{TiO}_{2}, \mathrm{Fe}_{2} \mathrm{O}_{3}, \mathrm{Co}_{3} \mathrm{O}_{4}\right.$, etc. $)$ via a depositionprecipitation (DP) or a coprecipitation (CP) method. In the case of nonreducible or "inert" supports such as $\mathrm{SiO}_{2}$, however, both DP and CP method fail to work because of the low isoelectric point of silica. From the viewpoint of surface science, because of a lack of anchoring sites (e.g., oxygen vacancies) on the silica support, ${ }^{12,13}$ silica-supporting gold particles are susceptible to aggregation upon thermal treatment, which causes a dramatic loss of activity. To prevent or reduce this sintering effect, many attempts have been made, including confining gold particles in the nanopores of a mesoporous support, ${ }^{14-17}$ trapping gold particles

(9) Chen, M. S.; Goodman, D. W. Science 2004, 306, 252.

(10) Haruta, M. Chem. Rec. 2003, 3, 75.

(11) Falsig, H.; Hvolbæk, B.; Kristensen, I. S.; Jiang, T.; Bligaard, T.; Christensen, C. H.; Nørskov, J. K. Angew. Chem., Int. Ed. 2008, 47, 4835.

(12) Min, B. K.; Wallace, W. T.; Goodman, D. W. Surf. Sci. 2006, 600, L7.

(13) Yan, Z.; Chinta, S.; Mohamed, A. A.; Fackler, J. P.; Goodman, D. W. J. Am. Chem. Soc. 2005, 127, 1604.

(14) Yang, C. M.; Liu, P. H.; Ho, Y. F.; Chiu, C. Y.; Chao, K. J. Chem. Mater. 2003, 15, 275.

(15) Bore, M. T.; Pham, H. N.; Switzer, E. E.; Ward, T. L.; Fukuoka, A.; Datye, A. K. J. Phys. Chem. B 2005, 109, 2873.

(16) Zhu, H.; Liang, C.; Yan, W.; Overbury, S. H.; Dai, S. J. Phys. Chem. B 2006, 110, 10842 .

(17) Sun, J.; Ma, D.; Zhang, H.; Liu, X.; Han, X.; Bao, X.; Weinberg, G.; Pfänder, N.; Su, D. J. Am. Chem. Soc. 2006, 128, 15756. 
in the matrix of the silica support by coassembly, ${ }^{18,19}$ and grafting a reducible oxide layer on the silica surface to adhere to the gold particles. ${ }^{20-22}$

Recently, we developed a facile two-step method for synthesis of $\mathrm{Au}-\mathrm{Cu}$ alloy particles, where the particle size was well-controlled at $2-3 \mathrm{~nm}$ in the nanochannels of SBA$15 .^{23}$ The employment of SBA-15 is presumably to confine the nanoparticles in the orderly arranged channels to prevent their sintering or agglomeration, as reported earlier by various groups. ${ }^{14-17}$ However, we found that even with a harsh treatment, e.g., calcination at $500^{\circ} \mathrm{C}$ in air for $6 \mathrm{~h}$ followed by reduction at $550{ }^{\circ} \mathrm{C}$ in $\mathrm{H}_{2}$ for $1 \mathrm{~h}$, the particle size of the $\mathrm{Au}-\mathrm{Cu}$ alloy was only around $3 \mathrm{~nm}$, which is far less than the pore size $(\sim 6 \mathrm{~nm})$ of the SBA-15 support. This result seems to suggest that the nanopores of the SBA-15 support have little effect in stabilizing the gold alloy particles. Potentially, the method can be developed into a general approach to synthesize very small and thermally stable gold alloy particles on a ubiquitous commercial support, such as silica and alumina. In the present work, we will demonstrate this approach by synthesizing highly dispersed $\mathrm{Au}-\mathrm{Ag}$ nanoparticles on a variety of inert supports. The $\mathrm{Au}-\mathrm{Ag}$ bimetallic systems are chosen based on the following reasons. First, there is no report so far on synthesis of highly dispersed and thermally stable $\mathrm{Au}-\mathrm{Ag}$ alloy nanoparticles on commercial silica or alumina supports in spite of its widespread applications in optics, electronics, and catalysis. In most cases, synthesis of $\mathrm{Au}-\mathrm{Ag}$ bimetallic nanoparticles is conducted in a solution based on a wet chemical reduction method and good control in both size and morphology can therefore be accomplished under the presence of protective agents (surfactants or polymers). ${ }^{24-28}$ However, when the nanoparticles with well defined structure and size in solution are deposited on a support and are subject to a thermal treatment for removing the protective agents, the original nanostructure, its size, and morphology are hardly retained due to heat- and atmosphere-induced sintering and restructuring. For example, in our earlier work, ${ }^{29-32} \mathrm{Au}-\mathrm{Ag}$ alloy particles with sizes smaller than $7 \mathrm{~nm}$ were prepared in an aqueous solution under the protection of hexadecyl trimethyl ammonium bromide (CTAB). However, upon deposition on

(18) Budroni, G.; Corma, A. Angew. Chem., Int. Ed. 2006, 45, 3328.

(19) Liu, H.; Ma, D.; Blackley, R. A.; Zhou, W.; Bao, X. Chem. Commun. 2008, 2677.

(20) Yan, W.; Mahurin, S. M.; Chen, B.; Overbury, S. H.; Dai, S. J. Phys. Chem. B 2005, 109, 15489.

(21) Horváth, A.; Beck, A.; Sárkány, A.; Stefler, G.; Varga, Z.; Geszti, O.; Tóth, L.; Guczi, L. J. Phys. Chem. B 2006, 110, 15417.

(22) Qian, K.; Huang, W.; Jiang, Z.; Sun, H. J. Catal. 2007, 248, 137.

(23) Liu, X.; Wang, A.; Wang, X.; Mou, C. Y.; Zhang, T. Chem. Commun. 2008, 3187.

(24) Mallin, M. P.; Murphy, C. J. Nano Lett. 2002, 2, 1235.

(25) Pande, S.; Ghosh, S. K.; Praharaj, S.; Panigrahi, S.; Basu, S.; Jana, S.; Pal, A.; Tsukuda, T.; Pal, T. J. Phys. Chem. C 2007, 111, 10806.

(26) Lee, I.; Han, S. W.; Kim, K. Chem. Commun. 2001, 1782.

(27) Yin, Y.; Erdonmez, C.; Aloni, S.; Alivisatos, A. P. J. Am. Chem. Soc. 2006, $128,12671$.

(28) Cobley, C. M.; Campbell, D. J.; Xia, Y. Adv. Mater. 2008, 20, 748.

(29) Liu, J. H.; Wang, A. Q.; Chi, Y. S.; Lin, H. P.; Mou, C. Y. J. Phys. Chem. B 2005, 109, 40.

(30) Wang, A. Q.; Liu, J. H.; Lin, S. D.; Lin, T. S.; Mou, C. Y. J. Catal. 2005, 233, 186.

(31) Wang, A.; Hsieh, Y. P.; Chen, Y. F.; Mou, C. Y. J. Catal. 2006, 237, 197.

(32) Wang, A. Q.; Chang, C. M.; Mou, C. Y. J. Phys. Chem. B 2005, 109, 18860.
MCM-41 support and calcination at $500{ }^{\circ} \mathrm{C}$ for removal of $\mathrm{CTAB}$, the particles were remarkably enlarged to $20-30 \mathrm{~nm}$. Although such large alloy particles are very active for $\mathrm{CO}$ oxidation, which is quite different from pure gold, they are completely deactivated by the presence of $\mathrm{H}_{2}$ in the reacting stream. We wonder if this deactivation is related to the large particle size, which stimulates us to search for a new method to synthesize very small and uniform $\mathrm{Au}-\mathrm{Ag}$ alloy particles on a commercial silica support. Second, although silver belongs to the same group as gold, it has very different properties from gold with regard to oxygen adsorption. As gold binds oxygen very weakly, oxygen activation is generally thought as a rate-limiting step for most oxidation reactions catalyzed by gold nanoparticles. ${ }^{33-35}$ In contrast, silver adsorbs oxygen very well and different oxygen species that are activated on silver surface have been identified. ${ }^{36,37}$ The intrinsically different properties of gold and silver toward oxygen activation have great potential to be fine-tuned for their synergetic effect in catalyzing various oxidation reactions. ${ }^{30,38}$ Third, and most importantly, in our recently reported $\mathrm{Au}-\mathrm{Cu}$ case, ${ }^{23}$ the presence of $\mathrm{Cu}$ was found to greatly limit the growth of the prepared particles, which led to a much smaller particle size for $\mathrm{Au}-\mathrm{Cu}$ than for pure gold. We wonder if the same trend exists in other gold-alloy systems, e.g., $\mathrm{Au}-\mathrm{Ag}$.

On the basis of these observations, we are interested in investigating if it is of general significance that the presence of a second metal stabilizes the gold particles to a relatively small size. The understanding of such questions may open up a new route for preparing highly thermally stable gold or gold alloy particles. In the present work, we have synthesized small sized and thermally stable $\mathrm{Au}-\mathrm{Ag}$ alloy particles on commercial silica and alumina support. We have shown that our approach is in principle applicable to a variety of supports provided that the support surface possesses rich hydroxyl groups and the presence of Ag plays a key role in stabilizing the particles. To uncover the underlying reason for the stabilizing effect, detailed investigations, step by step, into the structural changes occurring during the preparation and thermal treatment are conducted by employing HRTEM, UV-vis, and XPS techniques. In addition, theoretical investigations based on selected cluster models are also used to provide understanding of the stabilities and electronic properties of the nanoparticles formed. Finally, catalytic tests have shown that the $\mathrm{Au}-\mathrm{Ag}$ alloy nanoparticles on inert silica supports are very active for $\mathrm{CO}$ oxidation with or without the presence of $\mathrm{H}_{2}$, even more active than $\mathrm{Au} / \mathrm{TiO}_{2}$.

\section{Experimental Section}

2.1. Synthesis of Oxide-Supported $\mathbf{A u}-\mathbf{A g}$ Particles. The synthesis of $\mathrm{Au}-\mathrm{Ag}$ nanoparticles on silica support started with

(33) Mills, G.; Gordon, M. S.; Metiu, H. J. Chem. Phys. 2003, 118, 4198. (34) Deng, X.; Min, B. K.; Guloy, A.; Friend, C. M. J. Am. Chem. Soc. 2005, 127, 9267.

(35) Guzman, J.; Carrettin, S.; Corma, A. J. Am. Chem. Soc. 2005, 127, 3286.

(36) Qu, Z.; Huang, W.; Cheng, M.; Bao, X. J. Phys. Chem. B 2005, 109, 15842 .

(37) Qu, Z.; Cheng, M.; Huang, W.; Bao, X. J. Catal. 2005, 229, 446.

(38) Chaki, N. K.; Tsunoyama, H.; Negishi, Y.; Sakurai, H.; Tsukuda, T. J. Phys. Chem. C 2007, 111, 4885. 
adding $1 \mathrm{~g}$ of a commercial silica support (Qingdao Ocean Chemical Plant, $S_{\text {BET }}=467 \mathrm{~m}^{2} \mathrm{~g}^{-1}$ ) to a $50 \mathrm{~mL}$ ethanol solution containing $2.5 \mathrm{~g}$ of APTES $\left(\mathrm{H}_{2} \mathrm{~N}\left(\mathrm{CH}_{2}\right)_{3} \mathrm{Si}(\mathrm{OEt})_{3}\right.$, Acros $)$. The mixture was refluxed for $24 \mathrm{~h}$ to graft APTES on the silica surface. ${ }^{39,40}$ After being washed with ethanol and dried at $60{ }^{\circ} \mathrm{C}$, the solid was redispersed in $16 \mathrm{~g}$ of $\mathrm{H}_{2} \mathrm{O}$ at room temperature, to which $4 \mathrm{~mL}$ of $1.65 \mathrm{wt} \% \mathrm{HAuCl}_{4}$ solution was added under stirring. After filtration and washing, the recovered solid was added into $10 \mathrm{~g}$ of water, to which $10 \mathrm{~mL}$ of $0.2 \mathrm{M} \mathrm{NaBH}_{4}$ solution was added under vigorous stirring for reduction of $\mathrm{AuCl}_{4}^{-}$. After $20 \mathrm{~min}$, the solid was recovered by filtration and thoroughly washed with water to remove $\mathrm{Cl}^{-}$for the subsequent $\mathrm{Ag}$ deposition, which was the same as the above $\mathrm{Au}$ deposition except that $\mathrm{AgNO}_{3}$ was used as the precursor. Finally, the solid was calcined at $500{ }^{\circ} \mathrm{C}$ in air for $6 \mathrm{~h}$ and reduced at $550{ }^{\circ} \mathrm{C}$ in $\mathrm{H}_{2}$ for $1 \mathrm{~h}$ to obtain the $\mathrm{Au}-\mathrm{Ag} / \mathrm{SiO}_{2}$ catalyst. The same procedure was also applied to other supports including alumina $\left(S_{\mathrm{BET}}=198 \mathrm{~m}^{2} \mathrm{~g}^{-1}\right)$, nano silica $\left(S_{\mathrm{BET}}=201 \mathrm{~m}^{2} \mathrm{~g}^{-1}\right)$, and SBA-15 $\left(S_{\mathrm{BET}}=903 \mathrm{~m}^{2} \mathrm{~g}^{-1}\right)$, to obtain $\mathrm{Au}-\mathrm{Ag}$ nanoparticles with different supports. In all cases, the nominal total metal loading was 6 wt $\%$.

2.2. Characterization. The actual total metal loadings and the $\mathrm{Au} / \mathrm{Ag}$ atomic ratios of various $\mathrm{Au}-\mathrm{Ag} / \mathrm{SiO}_{2}$ samples were determined by inductively coupled plasma spectrometer (ICP-AES) on an IRIS Intrepid II XSP instrument (Thermo Electron Corporation). The surface $\mathrm{Au} / \mathrm{Ag}$ atomic ratios, along with the binding energies of gold and silver, were determined by XPS on an AMICUS X-ray photoelectron spectrometer equipped with a $\mathrm{Mg}$ $\mathrm{K} \alpha$ radiation $(1253.6 \mathrm{eV}, 10 \mathrm{kV}, 20 \mathrm{~mA}, 200 \mathrm{~W})$ under a residual pressure of $1 \times 10^{-6} \mathrm{~Pa}$. The raw data were corrected for substrate charging with the binding energy of the $\mathrm{Si}_{2 p}(103.4 \mathrm{eV})$ on a silica support as a reference. The recorded spectra were fit by a leastsquares procedure to a product of Gaussian-Lorentzian functions after subtraction of background noise. The concentration of each element was calculated from the area of the corresponding peak, calibrated with the atomic sensitivity factor. HRTEM analyses were performed with a Tecnai $\mathrm{G}^{2}$ F30 S-Twin Transmission Electron Microscope operating at $300 \mathrm{kV}$. A few droplets of a suspension of the sample in ethanol were put on a microgrid carbon polymer supported on a copper grid and allowed to dry at room temperature for HRTEM observations. The particle size distribution was obtained by measuring more than 200 particles from randomly selected areas. Chemical compositions of individual particles or different areas were determined by energy-dispersive X-ray spectroscopy (EDS) on a DX4 analyzer system which is attached to a Philips CM200 FEG electron microscope. X-ray Diffraction (XRD) patterns were recorded on a PW3040/60 X' Pert PRO (PANalytical) diffractometer equipped with a $\mathrm{Cu} \mathrm{K} \alpha$ radiation source $(\lambda=$ $0.15432 \mathrm{~nm}$ ), operating at $40 \mathrm{kV}$ and $40 \mathrm{~mA}$. A continuous mode was used for collecting data in the $2 \theta$ range from $20^{\circ}$ to $80^{\circ}$ at a scanning speed of $5^{\circ} \mathrm{min}^{-1}$. UV-vis spectra were recorded at room temperature on a Cintra (GBC) apparatus with $\mathrm{BaSO}_{4}$ as a reference.

2.3. Catalytic Reaction Tests. Catalytic activity was measured using a continuous flow fixed-bed reactor system. For CO oxidation, a feed stream containing $1.0 \mathrm{vol} \% \mathrm{CO}$ and $1.0 \mathrm{vol} \% \mathrm{O}_{2}$ balanced with He was allowed to pass through $60 \mathrm{mg}$ (20-40 mesh) of a catalyst sample at a flow rate of $20 \mathrm{~mL} \mathrm{~min}^{-1}$, corresponding to a space velocity of $20,000 \mathrm{~mL} \mathrm{~h}^{-1} \mathrm{~g}_{\text {cat }}{ }^{-1}$. For preferential $\mathrm{CO}$ oxidation in rich $\mathrm{H}_{2}$, the feed gas was composed of $1.0 \mathrm{vol} \% \mathrm{CO}$, 0.5 vol $\% \mathrm{O}_{2}$, and 50 vol $\% \mathrm{H}_{2}$ balanced with $\mathrm{He}$, and the total

(39) Tu, C. H.; Wang, A. Q.; Zheng, M. Y.; Wang, X. D.; Zhang, T. Appl. Catal., A 2006, 297, 40.

(40) Chiang, C. W.; Wang, A.; Wan, B. Z.; Mou, C. Y. J. Phys. Chem. B 2005, 109, 18042. flow rate was $40 \mathrm{~mL} \mathrm{~min}{ }^{-1}$ corresponding to a space velocity of $40000 \mathrm{~mL} \mathrm{~h}^{-1} \mathrm{~g}_{\mathrm{cat}}{ }^{-1}$. Prior to the reaction, the catalyst was pretreated with $\mathrm{H}_{2}$ at $550{ }^{\circ} \mathrm{C}$ for $1 \mathrm{~h}$ and then cooled to the reaction temperature under He. The inlet and outlet gas compositions were online analyzed by a gas chromatograph (HP 6890, TDX-01 column).

2.4. Density Functional Calculations. Our previous theoretical investigations indicate that with proper treatment of the relativistic effects and carefully selected exchange-correlation functional DFT methods can provide accurate information about geometries, electronic structures and properties of gold nanoclusters. ${ }^{41}$ Density functional calculations were performed with the program package $\mathrm{DMol}^{3}$ in the Materials Studio of Accelrys Inc. ${ }^{42,43}$ The localized double-numerical basis sets with polarization functions (DNP) were used, which are more accurate than but comparable in size to the Gaussian basis set $6-31 \mathrm{G}^{* *}$. Metal atom core electrons were treated using the quasi-relativistic pseudopotentials developed by Bergner et al., in which the mass-velocity and Darwin relativistic corrections were introduced. ${ }^{44}$ Generalized gradient approximation (GGA) using exchange-correlation functional developed by Perdew, Burke, and Ernzerhof (PBE) was employed. ${ }^{45}$ A real-space cutoff of $4.5 \AA$ was used, with convergence criteria of $2 \times 10^{-5}$ hartree $(1$ hatree $=$ $27.2 \mathrm{eV}), 4 \times 10^{-3}$ hartree/ $\AA$, and $5 \times 10^{-3} \AA$ for energy, energy gradient, and geometry, respectively. The self-consistent field (SCF) calculations were carried out with the spin-polarization Kohn-Sham formalism and molecular symmetry was not enforced to allow for geometry relaxation. Although the actual $\mathrm{Au}-\mathrm{Ag}$ nanoparticles are too large for the first-principle calculations, a series of model clusters $\mathrm{Au}_{38-x} \operatorname{Ag}_{x}(x=1,2)$ were constructed based on a facecentered cubic (FCC) octahedral $\mathrm{Au}_{38}$ cluster to model the bimetallic $\mathrm{Au}-\mathrm{Ag}$ nanoparticles with different compositions and structures.

\section{Results and Discussion}

\subsection{Synthesis of Au-Ag Nanoparticles on Silica and} Alumina Supports. The loading of gold and silver on the commercial silica is illustrated in Figure 1. In this procedure, the silica surface was first functionalized with amine to create anchoring sites for gold precursor. The negatively charged $\mathrm{AuCl}_{4}{ }^{-}$ions were then strongly adsorbed on the positively charged aminium ions in an acidic solution. The interaction between amine and gold precursor has been well documented in the literature, ${ }^{46,47}$ and this interaction was so strong that a relatively high amount of gold could be adsorbed on the amino-functionalized silica surface. ${ }^{40}$ After reduction with $\mathrm{NaBH}_{4}$, small-sized gold particles were produced on the functionalized silica surface and some of the amine groups were likely restored during the removal of $\mathrm{Cl}^{-}$ions in the washing process. Following that, $\mathrm{Ag}^{+}$cations were allowed to adsorb either on the free amine groups via complexation, or preferentially on the negatively charged gold particle surface via electrostatic attractions and metallic bonding. Our

(41) (a) Li, J.; Li, X.; Zhai, H. J.; Wang, L. S. Science 2003, 299, 864. (b) Ji, M.; Gu, X.; Li, X.; Gong, X. G.; Li, J.; Wang, L. S. Angew. Chem., Int. Ed. 2005, 44, 7119. (c) Gu, X.; Bulusu, S.; Li, X.; Zeng, X. C.; Li, J.; Gong, X. G.; Wang, L. S. J. Phys. Chem. C 2007, 111, 8228.

(42) Delley, B. J. Chem. Phys. 1990, 92, 508.

(43) Delley, B. J. Chem. Phys. 2000, 113, 7756.

(44) Bergner, A.; Dolg, M.; Küchle, W.; Stoll, H.; Preuss, H. Mol. Phys. 1993, 80, 1431.

(45) Perdew, J. P.; Burke, K.; Ernzerhof, M. Phys. Rev. Lett. 1996, 77, 3865 .

(46) Ghosh, A.; Patra, C. R.; Mukherjee, P.; Sastry, M.; Kumar, R. Microp. Mesop. Mater. 2003, 58, 201.

(47) Chi, Y. S.; Lin, H. P.; Mou, C. Y. Appl. Catal., A 2005, 284, 199. 

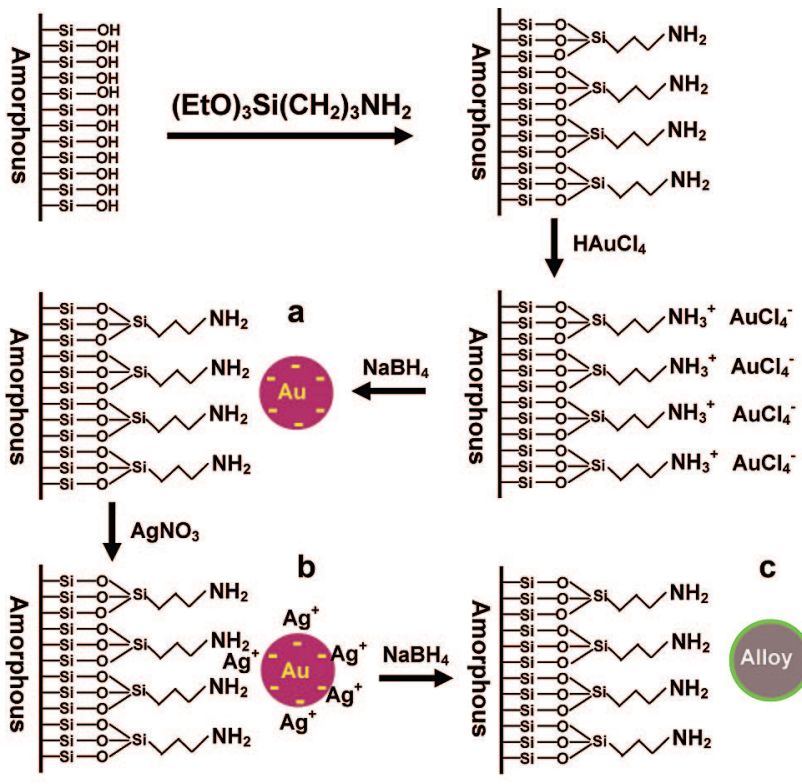

C
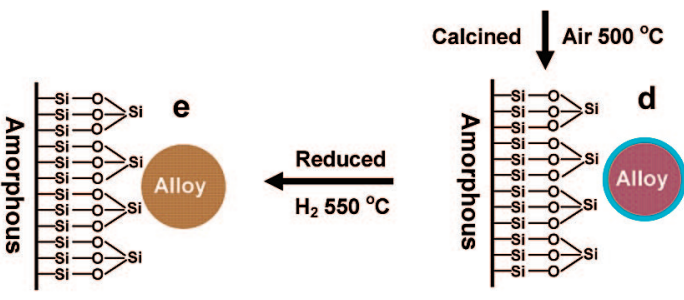

Ag shell

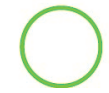

Ag oxide shell

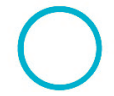

Figure 1. Schematic illustration of the procedure for synthesis of $\mathrm{SiO}_{2}$ supported $\mathrm{Au}-\mathrm{Ag}$ alloy nanoparticles. (a) Initially formed $\mathrm{Au}$ particles; (b) $\mathrm{AgNO}_{3}$ adsorbed on the $\mathrm{Au}$ particles; (c) $\mathrm{Au}-\mathrm{Ag}$ nanostructure with alloy core surrounded by silver shell; (d) $\mathrm{Au}-\mathrm{Ag}$ nanostructure with more gold-rich alloy core covered by $\mathrm{Ag}$ oxide shell; (e) random alloy of $\mathrm{Au}-\mathrm{Ag}$ nanoparticles on $\mathrm{SiO}_{2}$ support.

DFT calculations show that the latter case is predominant because of strong bimetallic interaction. In addition, we have discovered that loading gold prior to silver is pivotal for the control of the size and composition of the bimetallic particles. With a different loading sequence, either simultaneously or reversely, galvanic replacement reaction between $\mathrm{Ag}$ and $\mathrm{AuCl}_{4}{ }^{-}$will occur, ${ }^{28,48}$ which in addition to the formation of $\mathrm{AgCl}$ precipitate significantly induces the coalescence of particles upon heating treatment. The final calcination and reduction steps are necessary for removing the amine functional groups and for the formation of gold-silver particles on the support.

Figure 2 presents TEM images of the $\mathrm{Au}-\mathrm{Ag} / \mathrm{SiO}_{2}$ catalysts with different $\mathrm{Au} / \mathrm{Ag}$ atomic ratios. For comparison, monometallic $\mathrm{Au} / \mathrm{SiO}_{2}$ and $\mathrm{Ag} / \mathrm{SiO}_{2}$ were also examined. While $\mathrm{Au} / \mathrm{SiO}_{2}$ has an average particle size of $5.7 \mathrm{~nm}$ and $\mathrm{Ag} / \mathrm{SiO}_{2}$ of $7.6 \mathrm{~nm}$, the particle sizes become much smaller upon alloying $\mathrm{Au}$ with $\mathrm{Ag}, 3.3 \mathrm{~nm}$ for $\mathrm{Au} / \mathrm{Ag}=3 / 1$ and 3.4 $\mathrm{nm}$ for $\mathrm{Au} / \mathrm{Ag}=1 / 1$. Note this result is in contrary to the one-pot synthesized $\mathrm{Au}-\mathrm{Ag} @ \mathrm{MCM}-41$ system, ${ }^{32}$ where alloying gold with silver led to a remarkable increase of particle sizes. In that one-pot synthesis, $\mathrm{Br}^{-}$from the surfactant could combine with $\mathrm{Ag}^{+}$to form $\mathrm{AgBr}$, which in

(48) Sun, Y.; Xia, Y. J. Am. Chem. Soc. 2004, 126, 3892. turn caused the enlargement of $\mathrm{Au}-\mathrm{Ag}$ particles because of the much lower melting point of $\mathrm{AgBr}$ than that of metallic Ag. However, in our present approach, the silica surface was prefunctionalized with amine to create anchoring sites for $\mathrm{AuCl}_{4}{ }^{-}$. After reduction with $\mathrm{NaBH}_{4}$ and a thorough washing, the small gold particles were formed while $\mathrm{Cl}^{-}$was removed, which circumvented the formation of $\mathrm{AgCl}$ when $\mathrm{Ag}^{+}$was subsequently adsorbed on the surface. This is partly responsible for the small particle size of $\mathrm{Au}-\mathrm{Ag} / \mathrm{SiO}_{2}$. Consistent with the TEM observations, very broad XRD peaks (Figure 3) of the $\mathrm{Au}-\mathrm{Ag} / \mathrm{SiO}_{2}$ samples also indicate rather small particle sizes. It should be mentioned that, different from the case of $\mathrm{Au}-\mathrm{Cu},{ }^{23}$ the XRD patterns of gold and silver are totally overlapped so that one cannot distinguish $\mathrm{Au}-\mathrm{Ag}$ bimetallic phase from either monometallic phase based on the XRD patterns. ${ }^{30}$ However, from EDS analyses (see Figure S1 in the Supporting Information), one can clearly see that each individual particle on the $\mathrm{Au}-\mathrm{Ag} / \mathrm{SiO}_{2}$ sample is composed of both $\mathrm{Au}$ and $\mathrm{Ag}$. This result provides unequivocal evidence for the formation of bimetallic $\mathrm{Au}-\mathrm{Ag}$ particles. It is also noted that although the $\mathrm{Au} / \mathrm{Ag}$ ratio varies from one particle to another, the average $\mathrm{Au} / \mathrm{Ag}$ atomic ratio, which was obtained by EDS analyses on randomly selected areas (see Figure S2 in the Supporting Information), agrees well with the nominal value.

It is intriguing to note that the particle size of gold on the silica surface here is essentially identical to that on the SBA15 obtained in our previous work, ${ }^{23}$ indicating that the particle size is not determined by the pore size of the support. In our previous work, $\mathrm{Au}-\mathrm{Cu}$ alloy particles with an average size of $2.9 \mathrm{~nm}$ were formed in the nanochannels of SBA15. However, $2.9 \mathrm{~nm}$ is much smaller than the pore size of SBA-15 $(5.7 \mathrm{~nm})$, implying that the particle size is determined by the thermodynamics associated with the special nanostructure of the particles, rather than by the pore size of the support. Actually, $\mathrm{Au}-\mathrm{Cu}$ alloy particles with an average size of $3.4 \mathrm{~nm}$ can also be obtained on the commercial silica (see Figure S3 in the Supporting Information) in our present work, although this support has no orderly arranged regular pores. To further confirm that the particle size has little to do with the pore size of the support, we here synthesized $\mathrm{Au}-\mathrm{Ag}$ alloy particles with the same procedure on a variety of different supports including SBA15, nano silica, and alumina. In spite of the differences in the pore structures and chemical compositions of the supports employed (see Figure S4 in the Supporting Information), very small and uniform $\mathrm{Au}-\mathrm{Ag}$ nanoparticles were produced in each case (see Figure S5 in the Supporting Information). All the above results clearly demonstrate that the present twostep approach provides a general strategy for synthesizing small, uniform, and thermally stable gold-based bimetallic particles on a variety of different supports.

To probe the key factors responsible for the size of bimetallic gold particles, we conducted several control experiments. First, we performed the same synthesis on the nonfunctionalized $\mathrm{SiO}_{2}$ support and obtained a large and broad-size distribution of the $\mathrm{Au}-\mathrm{Ag}$ particles (see Figure S6 in the Supporting Information). This result clearly shows that the surface functionalization with amine groups is a 



Figure 2. HRTEM images and the corresponding particle size distributions of $\mathrm{Au}-\mathrm{Ag} / \mathrm{SiO}_{2}$ with various $\mathrm{Au} / \mathrm{Ag}$ atomic ratios: (a) 1/0, (b) 3/1, (c) $1 / 1$, (d) $0 / 1$.

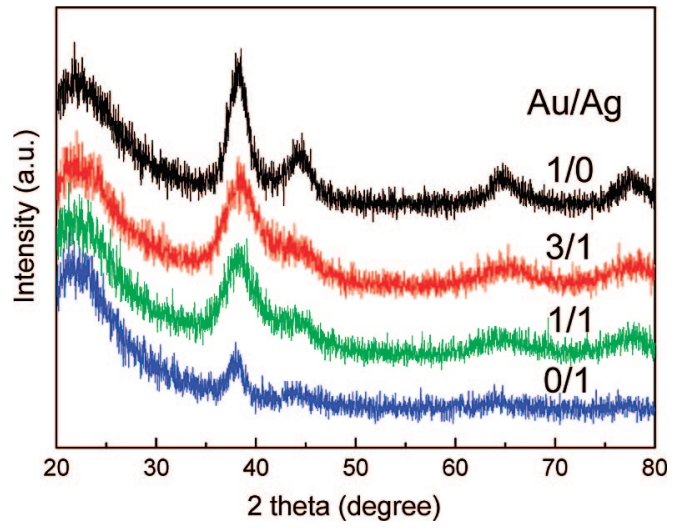

Figure 3. $\mathrm{XRD}$ patterns of $\mathrm{Au}-\mathrm{Ag} / \mathrm{SiO}_{2}$ with various $\mathrm{Au} / \mathrm{Ag}$ atomic ratios.

prerequisite for avoiding agglomeration of the particles. Second, we find that the reduction of gold precursor with $\mathrm{NaBH}_{4}$ is also indispensable for obtaining the very small bimetallic gold particles. Other reducing agents, including formaldehyde, hydrazine, and $\mathrm{H}_{2}$, all led to large particle size. Possibly, some amine-borane complexes could have been formed during the reduction process, ${ }^{49}$ which would act as a special reducing agent for obtaining very small bimetallic gold particles. Third and most importantly, it is found that the presence of $\mathrm{Ag}$ greatly limits the growth of gold particles in our two-step approach. Based on the XRD peak width of $\mathrm{Au} / \mathrm{Ag}$ (111) of the samples that had been calcined at different temperatures, we calculated the average particle size by Scherrer's equation. As shown in Figure 4, one can see that although the as-synthesized (dried at 80 ${ }^{\circ} \mathrm{C}$ ) gold particles are smaller than the gold-silver bimetallic particles, significant sintering occurred on pure gold particles upon calcination at $500{ }^{\circ} \mathrm{C}$, which led to a sharp increase of average particle size from 1.8 to $4.1 \mathrm{~nm}$. By contrast, the

(49) Zheng, N.; Fan, J.; Stucky, G. D. J. Am. Chem. Soc. 2006, 128, 6550.

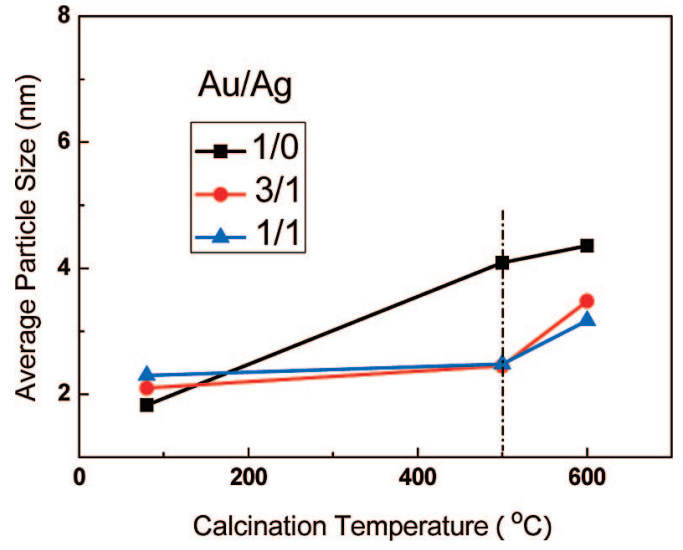

Figure 4. Changes in the average particle size with the calcination temperature. The average particle size was determined by Scherrer's equation according to the corresponding XRD spectra. The vertical line denotes the calcination temperature at $500{ }^{\circ} \mathrm{C}$.

gold-silver bimetallic particles are highly resistant to hightemperature calcinations, with the average particle size being essentially unchanged after $500{ }^{\circ} \mathrm{C}$ calcination. It should be pointed out that the average particle size estimated from XRD is smaller than that obtained from TEM measurements, possibly because some particles are too small to be observed by TEM.

3.2. Structural Evolution during Preparation and Thermal Treatment. To uncover the underlying reason for the high thermal stability of the $\mathrm{Au}-\mathrm{Ag}$ nanoparticles, in particular the key role of Ag in stabilizing the gold particles, we investigated in detail the structural evolution during each step of the preparation. As shown in Figure 5a, when $\mathrm{AuCl}_{4}{ }^{-}$ was adsorbed on the APTS-functionalized silica surface and reduced by $\mathrm{NaBH}_{4}$, very small and uniform gold particles (2.9 $\pm 0.7 \mathrm{~nm}$ ) were produced. These gold particles were deposited on the silica surface possibly via interacting with the amino groups (Figure 1a). The UV-vis spectrum of the sample at this stage (Figure 6a) also shows a very broad peak centered at $525 \mathrm{~nm}$, which is characteristic of surface plasma resonance 

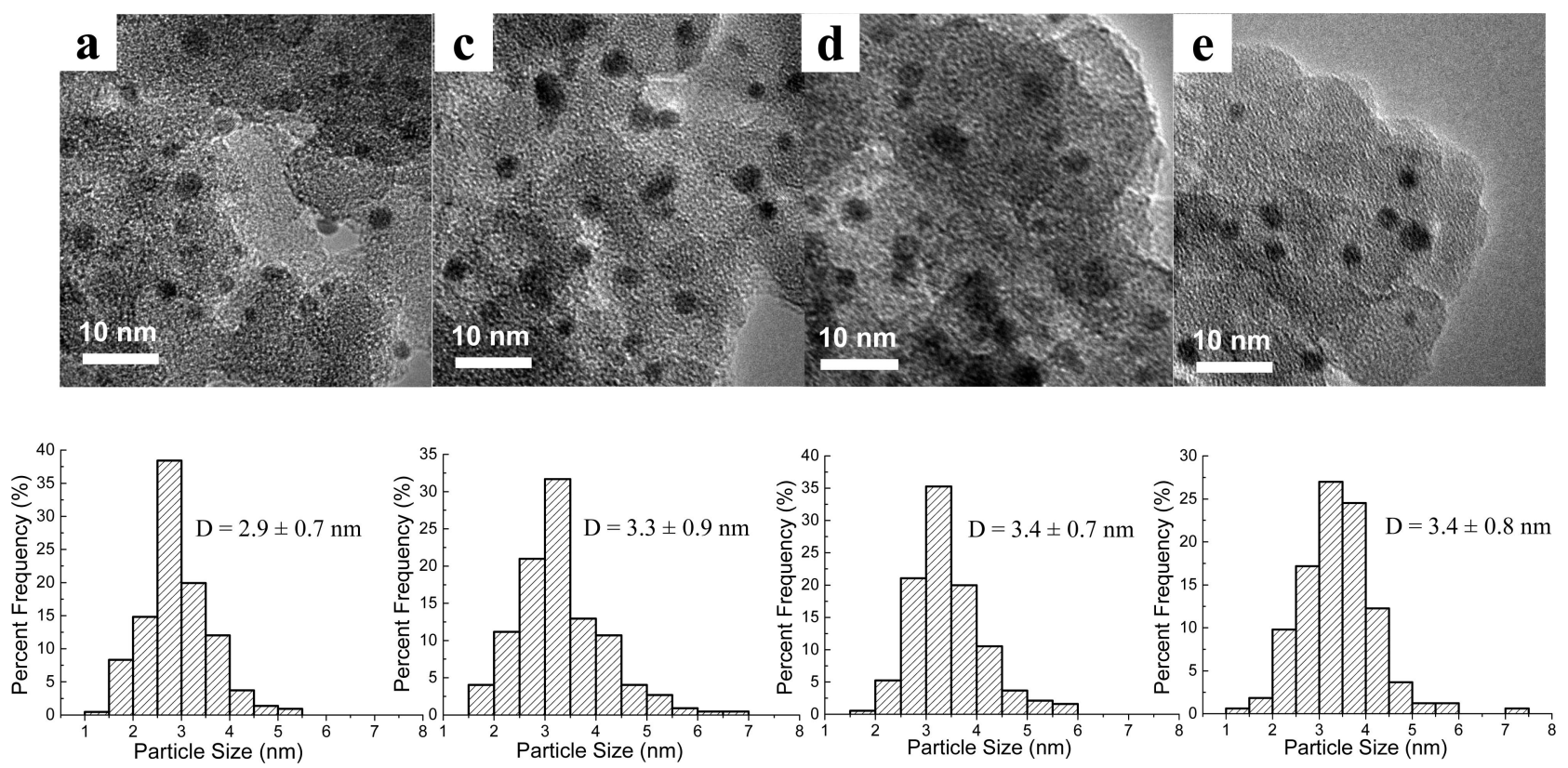

Figure 5. HRTEM images and the corresponding particle size distributions of $\mathrm{Au}-\mathrm{Ag} / \mathrm{SiO}_{2}(\mathrm{Au} / \mathrm{Ag}=1 / 1)$ at different preparation stages. (a), (c), (d), and (e) correspond to those in Figure 1.

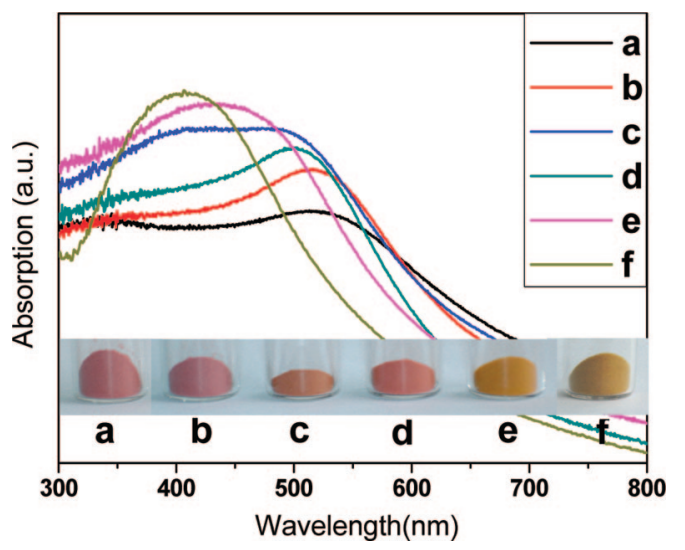

Figure 6. UV-vis spectra of $\mathrm{Au}-\mathrm{Ag} / \mathrm{SiO}_{2}(\mathrm{Au} / \mathrm{Ag}=1 / 1)$ at different preparation stages. The samples of $(\mathrm{a}-\mathrm{e})$ correspond to those in Figure 1. (f) $\mathrm{Ag} / \mathrm{SiO}_{2}$ obtained by the same method as sample a. The maximum of the absorption band is as follows: (a) 525, (b) 520, (c) 493 and 406, (d) 500, (e) 436, and (f) $406 \mathrm{~nm}$.

(SPR) of gold nanoparticles. ${ }^{50}$ Prior to adsorbing $\mathrm{Ag}^{+}$in the subsequent step, the sample was thoroughly washed with deionized water until no $\mathrm{Cl}^{-}$in the filtrate could be detected by $\mathrm{Ag}^{+}$. This washing step is proved to be very important because even trace amount of $\mathrm{Cl}^{-}$residue would result in the formation of $\mathrm{AgCl}$ precipitate on the sample surface upon adsorption of $\mathrm{Ag}^{+}$in the subsequent step, which in turn induces significantly the coalescence of particles during the final step of heat treatment due to the low melting point $\left(455^{\circ} \mathrm{C}\right)$ of $\mathrm{AgCl}$. Subsequently, $\mathrm{Ag}^{+}$cations were adsorbed on the preformed gold particle surface, or adsorbed on the amino groups that had been released. Considering that the amino groups tend to be positively charged in acidic $\mathrm{AgNO}_{3}$ solution, they are difficult to bind $\mathrm{Ag}^{+}$cations because of electrostatic repulsion. This is also supported by the relatively low loading efficiency of $\mathrm{Ag}$ compared with gold on the amino-functionalized silica. For example, when a nominal amount of $6 \mathrm{wt} \%$ metal ( $\mathrm{Au}$ or $\mathrm{Ag}$ )

(50) Link, S.; EI-Sayed, M. A. J. Phys. Chem. B 1999, 103, 4212.
Table 1. Calculated Average Bonding Energy $\left(E_{\text {avg }}\right)$ and Impurity Solution Energy ( $\left.\Delta E_{\text {imp }}\right)$ for Pure or Impure Nanoparticles

\begin{tabular}{llcc}
\hline clusters & & $E_{\text {avg }}{ }^{a}(\mathrm{eV})$ & $\Delta E_{\text {imp }}{ }^{b}(\mathrm{eV})$ \\
\hline $\mathrm{Au}_{38}$ & & 2.231 & \\
$\mathrm{Au}_{37} \mathrm{Ag}^{c}$ & face & 2.214 & -0.199 \\
& edge & 2.213 & -0.165 \\
& center & 2.237 & -0.477 \\
$\mathrm{Au}_{36} \mathrm{Ag}_{2}$ & & 2.242 &
\end{tabular}

${ }^{a}$ Average bonding energy on each metal atom on clusters. ${ }^{b}$ Impurity solution energy, which was calcualted according to $\Delta E_{\text {imp }}=E\left(\mathrm{Au}_{N-1} \mathrm{M}\right)$ - $E\left(\mathrm{Au}_{N}\right)+(1 / N)\left[E\left(\mathrm{Au}_{N}\right)-E\left(M_{N}\right)\right] .{ }^{c}$ Different location of impure metal atom was considered.

was attempted to be loaded on the amino-functionalized silica, the actual Ag loading was only $0.90 \mathrm{wt} \%$, whereas Au was $5.72 \mathrm{wt} \%$. On the other hand, the loading efficiency of $\mathrm{Ag}$ could be increased significantly when gold particles were preformed on the functionalized silica surface (see Table 2 in section 3.4). Our DFT calculations also show that the gold cluster surface carries slightly negative charges, which allows the $\mathrm{Ag}^{+}$cations to be adsorbed on its surface via electrostatic and metallic interactions. Therefore, we believe that at this stage, $\mathrm{Ag}^{+}$ions were predominantly adsorbed on the preformed gold particle surface, and the UV-vis spectrum at this time still reflects the characteristic SPR of gold nanoparticles (Figure 6b). Following the reduction by $\mathrm{NaBH}_{4}$, a silver nanoshell was produced on the gold core. According to the literature, ${ }^{48,51}$ whereas the silver atoms in the outer shell still remain as a pure silver phase, the silver atoms that are in close contact with the gold surface will diffuse into the gold core to form a gold-silver alloy phase due to the stronger bimetallic bonding, which is confirmed by our DFT calculations (see below). Thus, the UV-vis spectrum at this stage presents two distinct SPR bands (Figure 6c): one is centered at $493 \mathrm{~nm}$ and has a blue shift of $32 \mathrm{~nm}$ comparing to pure gold, which can therefore be assigned to the SPR of $\mathrm{Au}-\mathrm{Ag}$ alloy phase. The other is centered at

(51) Shibata, T.; Bunker, B. A.; Zhang, Z.; Meisel, D.; Vardeman II, C. F.; Gezelter, J. D. J. Am. Chem. Soc. 2002, 124, 11989. 
Table 2. Chemical Compositions of $\mathrm{Au}-\mathrm{Ag} / \mathrm{SiO}_{2}$ Catalysts determined by ICP and Their Turnover Frequencies (TOFs) in CO Oxidation

\begin{tabular}{|c|c|c|c|c|c|c|c|}
\hline catalysts & $\begin{array}{l}\text { actual total metal } \\
\text { loading }(\mathrm{wt} \%)^{a}\end{array}$ & $\begin{array}{c}\text { nominal } \mathrm{Au} / \mathrm{Ag} \\
\text { (atomic ratio) }\end{array}$ & $\begin{array}{l}\text { actual } \mathrm{Au} / \mathrm{Ag} \\
\left(_{(\text {atomic }} \text { ratio) }\right.\end{array}$ & $\begin{array}{l}\text { avg particle } \\
\text { size }(n m)^{b}\end{array}$ & $\begin{array}{c}\text { specific rate } \\
\left(\mathrm{mol}_{\mathrm{CO}} \mathrm{g}_{\mathrm{Au}}{ }^{-1} \mathrm{~h}^{-1}\right)\end{array}$ & $\begin{array}{c}\text { contact time } \\
\left(\mathrm{g}_{\text {cat }} \mathrm{h} \mathrm{mol} \mathrm{CO}^{-1}\right)\end{array}$ & $\begin{array}{l}\text { TOF } \\
\left(s^{-1}\right)\end{array}$ \\
\hline $\mathrm{Au} / \mathrm{SiO}_{2}$ & 5.72 & $1 / 0$ & $1 / 0$ & 5.7 & $0.10^{c}$ & $4.3^{c}$ & $0.02^{c}$ \\
\hline $\mathrm{Au}-\mathrm{Ag} / \mathrm{SiO}_{2}$ & 5.56 & $3 / 1$ & $3.18 / 1$ & 3.3 & $0.92^{c}$ & $2.2^{c}$ & $0.13^{c}$ \\
\hline $\mathrm{Au}-\mathrm{Ag} / \mathrm{SiO}_{2}$ & 4.85 & $1 / 1$ & $1.91 / 1$ & 3.4 & $0.52^{c}$ & $2.2^{c}$ & $0.08^{c}$ \\
\hline $\mathrm{Ag} / \mathrm{SiO}_{2}$ & $1.68^{d}$ & $0 / 1$ & $0 / 1$ & 7.6 & $0.01^{e}$ & 103 & 0.002 \\
\hline $\mathrm{Au} / \mathrm{TiO}_{2}^{f}$ & 1.01 & & $1 / 0$ & 2.1 & $0.77^{c}$ & $2.2^{c}$ & $0.07^{c}$ \\
\hline gold - organic $-\mathrm{SiO}_{2}$ & 1.7 & & & 3.6 & $0.48^{g}$ & 93 & \\
\hline
\end{tabular}

${ }^{a}$ Determined by ICP. ${ }^{b}$ Determined by HRTEM. ${ }^{c}$ Obtained at $20{ }^{\circ} \mathrm{C}$ by controlling the CO conversion at below $10 \%$ via diluting with SiC. ${ }^{d}$ The loading was obtained by twice deposition. ${ }^{e}$ The unit of the specific rate is $\mathrm{mol}_{\mathrm{CO}} \mathrm{g}_{\mathrm{Ag}}{ }^{-1} \mathrm{~h}^{-1}$. ${ }^{f}$ Provided by the World Gold Council. ${ }^{g}$ Obtained at $30{ }^{\circ} \mathrm{C}$ in ref 18 .

$406 \mathrm{~nm}$ and is characteristic of pure silver nanoparticles. Inasmuch as the penetration depth of incident light $(29 \mathrm{~nm}$ for $\mathrm{Ag}$ and $37 \mathrm{~nm}$ for $\mathrm{Au}$ ) is much greater than the sizes of the particles studied here, ${ }^{52}$ we can observe the absorption bands from both the surface silver nanoshell and the underlying $\mathrm{Au}-\mathrm{Ag}$ alloy core. TEM image in Figure $5 \mathrm{c}$ also demonstrates that after deposition of silver on gold, the average particle size was slightly enlarged from 2.9 to $3.3 \mathrm{~nm}$, which is in accordance with our proposed model of a thin nanoshell surrounding the $\mathrm{Au}-\mathrm{Ag}$ alloy core (as shown in Figure 1c). Calcination in air at $500{ }^{\circ} \mathrm{C}$ is necessary for removal of the amine ligand because any residue amine on the surface will significantly deactivate the catalyst. Unfortunately, this high-temperature treatment will induce, in most cases, severe sintering of nanoparticles for thermodynamic reasons. Comparing Figure 5a with Figure 2a, one can see that indeed gold nanoparticles without alloying with silver grow significantly from the original $2.9 \mathrm{~nm}$ to the aftercalcination $5.7 \mathrm{~nm}$. In remarkable contrast, the gold-silver bimetallic nanoparticles, with $\mathrm{Au}-\mathrm{Ag}$ alloy core and an $\mathrm{Ag}$ nanoshell, can endure such harsh treatment, with the particle size remaining essentially unchanged $(3.3 \mathrm{~nm}$ in Figure $5 \mathrm{c}$ vs $3.4 \mathrm{~nm}$ in Figure 5d) after calcination at $500{ }^{\circ} \mathrm{C}$. From the UV-vis spectrum in Figure 6d, it is clear that after the calcination treatment, the SPR band from the silver nanoshell disappeared while the SPR band from the $\mathrm{Au}-\mathrm{Ag}$ alloy redshifted from 493 to $500 \mathrm{~nm}$. The disappearance of the SPR band at $406 \mathrm{~nm}$ is most likely due to the oxidation of silver nanoshell by air to form silver oxide, which is transparent to the incident light. On the other hand, the red-shift of the SPR band of the gold-silver alloy core may be due to the segregation of silver to the surface induced by high-temperature calcination, ${ }^{30,53}$ which makes the alloy core more gold-rich. This can also be visualized by the color change from yellow brown to red brown after the calcination treatment. Since significant sintering took place on pure gold nanoparticles during such high-temperature calcination while gold-silver bimetallic nanostructure was prettily sintering-resistant, we speculate that it is the silver oxide layer formed on the gold-silver alloy core that prevents the particles from sintering.

Our catalytic test shows that such nanoparticles with a silver oxide layer covering the gold-silver alloy core are totally inactive for $\mathrm{CO}$ oxidation at room temperature. To further activate the catalyst, a high-temperature reduction in $\mathrm{H}_{2}$ atmosphere proved to be necessary. Such a reduction treatment did not induce the sintering of particles, but indeed

(52) Shi, H.; Zhang, L.; Cai, W. J. Appl. Phys. 2000, 87, 1572.

(53) González, S.; Neyman, K. M.; Shaikhutdinov, S.; Freund, H. J.; Illas, F. J. Phys. Chem. C 2007, 111, 6852. restructured the particles. As shown in Figure 6e, after the reduction treatment, the SPR band of the sample had a large blue-shift from 500 to $436 \mathrm{~nm}$. The existence of only one peak indicates the formation of gold-silver alloy while its broadness may be due to the nonuniform $\mathrm{Au} / \mathrm{Ag}$ ratio from one particle to another. Our EDS analyses (see Figure S1 in the Supporting Information) of different particles also confirmed this. The nonuniform composition may result from the varied amount of $\mathrm{Ag}^{+}$which was adsorbed on each gold core. The large blue-shift of the SPR band after the $\mathrm{H}_{2}$ reduction suggests that more silver atoms are alloyed with gold during that process. This can be easily understood considering that the silver oxide is reduced to metallic silver and the interdifussion between $\mathrm{Au}$ and $\mathrm{Ag}$ atoms drives completely random alloying of gold and silver. The structure changes of the nanoparticles during each step are also schematically illustrated in Figure 1.

The above proposed model was further supported by the changes of surface $\mathrm{Au} / \mathrm{Ag}$ atomic ratios which were determined by XPS. It should be pointed out that the binding energies (B.E.) of gold and silver for all the $\mathrm{Au}-\mathrm{Ag}$ bimetallic samples we detected are characteristic of metallic gold and oxidized silver ${ }^{54}$ (B.E. of $\mathrm{Au}_{4 \mathrm{f} 7 / 2}$ varied from 83.3 to $83.5 \mathrm{eV}$, whereas that of $\mathrm{Ag}_{3 \mathrm{~d} 5 / 2}$ varied from 367.4 to 367.6 $\mathrm{eV}$ for different samples, see Figure S7 and Table S1 in the Supporting Information). The absence of metallic Ag may be due to exposure to air during sample handling. Therefore, we just focus on the surface $\mathrm{Au} / \mathrm{Ag}$ ratios. The surface $\mathrm{Au} /$ $\mathrm{Ag}$ atomic ratio of the sample in Figure 1c is 1.60, which is significantly lower than the bulk value (determined by ICP) of 1.91 (see Table 2 in section 3.4). Clearly, the surface of the bimetallic nanoparticle at this stage is enriched with $\mathrm{Ag}$, which is in accordance with our proposed model of a thin silver layer covering on the $\mathrm{Au}-\mathrm{Ag}$ alloy core. When the sample in Figure 1c was calcined in air at $500{ }^{\circ} \mathrm{C}$ (producing the sample in Figure 1d), the surface enrichment of silver became more pronounced, as indicated by the surface $\mathrm{Au} /$ $\mathrm{Ag}$ atomic ratio of only 1.48. Evidently, the high-temperature calcination in air induces further segregation of $\mathrm{Ag}$ to the surface, leaving a more gold-rich $\mathrm{Au}-\mathrm{Ag}$ alloy core. This result agrees well with our UV-vis spectra. After the final reduction by $\mathrm{H}_{2}$, the surface $\mathrm{Au} / \mathrm{Ag}$ atomic ratio (1.89) becomes very close to the bulk value, confirming the realloying of gold and silver to form a completely random

(54) Chimentăo, R. J.; Kirm, I.; Medina, F.; Rodríguez, X.; Cesteros, Y.; Salagre, P.; Sueiras, J. E.; Fierro, J. L. G. Appl. Surf. Sci. 2005, 252, 793. 

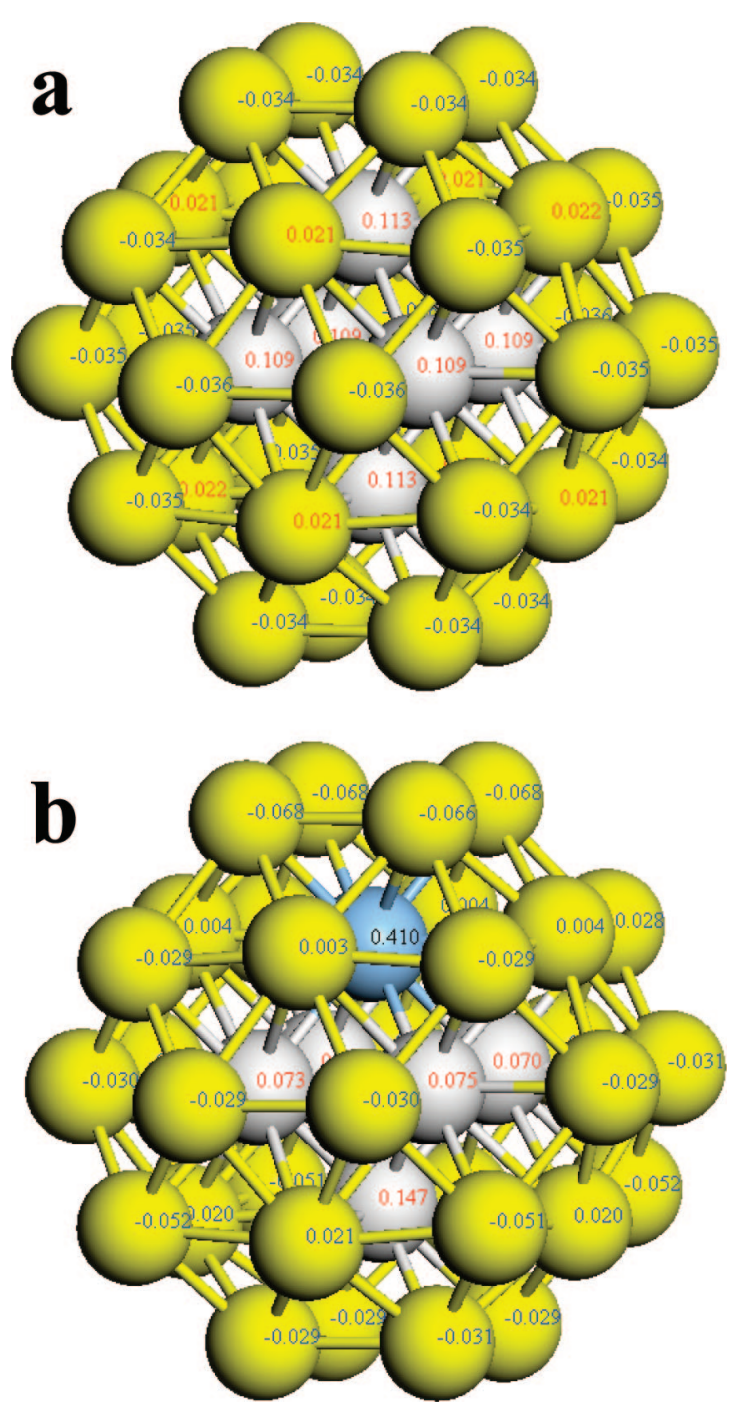

Figure 7. Mulliken net charges on (a) $\mathrm{Au}_{38}$ cluster; (b) $\mathrm{Au}_{37} \mathrm{Ag}$ cluster. Gray, inner gold atoms; yellow, outer gold atoms; blue, silver atom.

alloy during the reduction process. Upon complete alloying, the particles became very active for $\mathrm{CO}$ oxidation.

3.3. Understanding the Exceptional Thermal Stability by DFT Calculation. From the above experimental results one can see that $\mathrm{Ag}$ plays a key role in stabilizing the gold alloy particles on inert silica and alumina support. For a better understanding of such a stabilizing role, we performed quasirelativistic density functional calculations on a series of model clusters $\mathrm{Au}_{38-x} \operatorname{Ag}_{x}(x=0,1,2)$ to elucidate the nature of the interactions between the two components of the bimetallic alloy. All these nanoclusters were constructed based on a face-centered cubic (FCC) octahedral $\mathrm{Au}_{38}$ cluster. ${ }^{55,56}$ As shown in Figure 7 , the low-coordinated surface atoms of the pure $\mathrm{Au}_{38}$ cluster carry slightly negative charges, which will allow the $\mathrm{Ag}^{+}$ions to be preferentially adsorbed on the gold nanoparticle surface rather than on those free amine ligands. Moreover, it was found that when one $\mathrm{Ag}$ atom is incorporated in the $\mathrm{Au}_{38}$ cluster to substitute one Au atom, the $\mathrm{Ag}$ atom tends to go into the cluster center rather than stay on the surface layer (edge or face), as

(55) Li, T. X.; Yin, S. Y.; Ji, Y. L.; Wang, B. L.; Wang, G. H.; Zhao, J. J. Phys. Lett. A 2000, 267, 403.

(56) Garzón, I. L.; Michaelian, K.; Beltrán, M. R.; Posada-Amarillas, A.; Ordejón, P.; Artacho, E.; Sánchez-Portal, D.; Soler, J. M. Phys. Rev. Lett. 1998, 81, 1600. indicated by the increased average bonding energies (Table 1, $2.231 \mathrm{eV}$ for $\mathrm{Au}_{38}$ and $2.237 \mathrm{eV}$ for $\mathrm{Au}_{37} \mathrm{Ag}$ ). The calculated impurity solution energy of $\mathrm{Au}_{37} \mathrm{Ag}$ is $-0.477 \mathrm{eV}$, suggesting that alloying gold with silver is drastically exothermic and thermodynamically favorable. These calculation results on the model clusters are in good agreement with our experimental observations. When silver atoms are deposited on the preformed gold nanoparticles, those subsurface $\mathrm{Ag}$ atoms in close contact with the gold particle surface will spontaneously diffuse into the gold cluster to form the gold-silver alloy. The increased bonding energies of $\mathrm{Au}_{37} \mathrm{Ag}$ and $\mathrm{Au}_{36} \mathrm{Ag}_{2}$ also suggest that the alloy phase should have a higher melting point than the pure gold clusters. Because of the large heteronuclear $\mathrm{Au}-\mathrm{Ag}$ bonding, when more silver atoms are incorporated, as in the actual $\mathrm{Au}-\mathrm{Ag}$ bimetallic nanoparticles with $\sim 3 \mathrm{~nm}$ size, the average bonding energies will become even higher, and thereby the rise of the melting temperature will become more pronounced. In agreement with our calculation results, Cheng et al. ${ }^{57}$ reported that doping of $\mathrm{Au}_{55}$ with a single $\mathrm{Cu}$ atom can sharply raise the melting point of the cluster. Similarly, through molecular dynamics simulations of the thermal behavior of 55atom $\mathrm{Au}-\mathrm{Ag}$ nanoalloys it is demonstrated that the melting temperature progressively goes up with increasing the $\mathrm{Ag}$ content. ${ }^{58}$ Thus, the increased melting point by alloying gold with silver should be partially responsible for the thermal stability of the $\mathrm{Au}-\mathrm{Ag}$ nanoparticles. On the other hand, the most important factor for the thermal stability of the small-size $\mathrm{Au}-\mathrm{Ag}$ particles, we believe, is due to the outmost $\mathrm{Ag}$ nanoshell covering the $\mathrm{Au}-\mathrm{Ag}$ alloy core. As the $\mathrm{Ag}$ atoms are attached to the Au particles preformed in the first step, these "surface" Ag atoms are more easily oxidized during the calcination. Consistent with this notion, our DFT calculations show that the Ag atoms on the surface layer of the model cluster carry significant positive charges because of the different electronegativities for $\mathrm{Ag}$ and $\mathrm{Au}$. These partially positively charged $\mathrm{Ag}$ atoms can therefore be easily oxidized during calcination in the air. The thus formed oxides serve as passivated agents that prevent the coalescence of the $\mathrm{Au}-\mathrm{Ag}$ particles to form larger particles. From a more general viewpoint, the surface $\mathrm{Ag}$ oxide layer is just like a nanoglue that adheres strongly the inside nanoparticles to the silica support via $\mathrm{Ag}-\mathrm{O}-\mathrm{Si}$ linkages because oxides generally have a stronger interaction than the corresponding metals with the support. This effect is reminiscent of traditional metal-support interaction, which is often tuned by some promoters just like a nanoglue. ${ }^{59}$ The uniqueness of our present $\mathrm{Au}-\mathrm{Ag}$ bimetallic nanostructure is that the nanoparticles are prevented from sintering under hightemperature oxidizing atmosphere because of formation of passivated layer while these nanoparticles can be activated by reducing the passivated oxide layer to reform the $\mathrm{Au}-\mathrm{Ag}$ alloy phase.

3.4. Reactivity of $\mathrm{Au}-\mathrm{Ag}$ Nanoparticles toward $\mathrm{CO}$ Oxidation. Inasmuch as the $\mathrm{Au}-\mathrm{Ag}$ particles are rather small and highly dispersed, they exhibit high activities toward CO

(57) Cheng, D.; Huang, S.; Wang, W. Phys. Rev. B 2006, 74, 064117-1.

(58) Chen, F.; Curley, B. C.; Rossi, G.; Johnston, R. L. J. Phys. Chem. C 2007, 111, 9157

(59) Schubert, M. M.; Kahlich, M. J.; Feldmeyer, G.; Hüttner, M.; Hackenberg, S.; Gasteiger, H. A.; Behm, R. J. Phys. Chem. Chem. Phys. 2001, 3, 1123. 

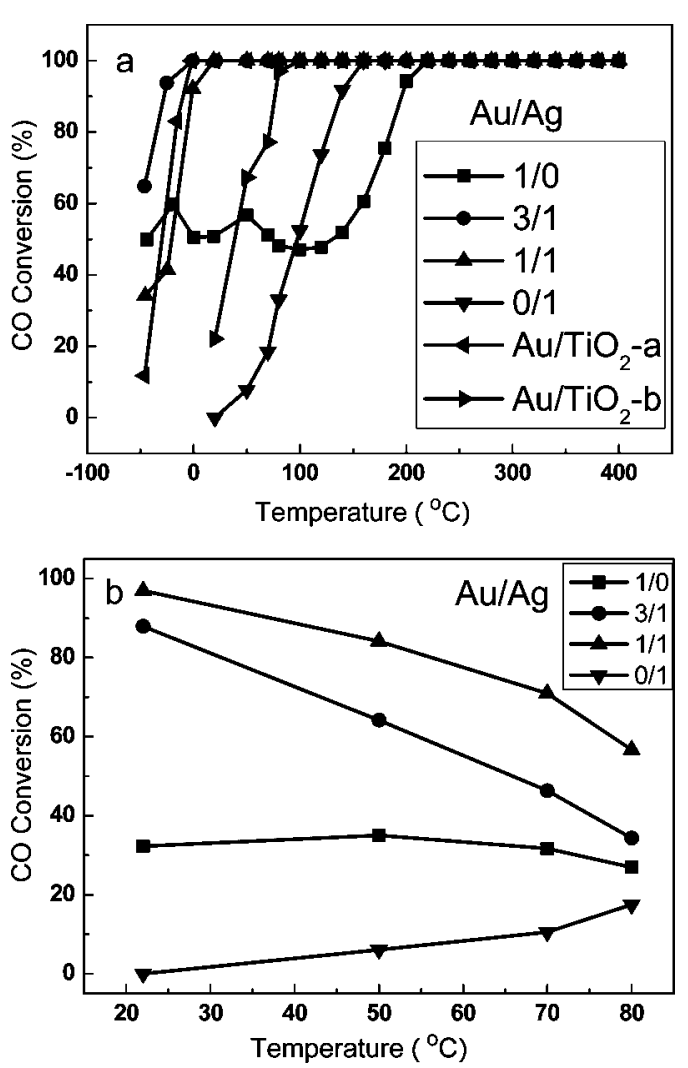

Figure 8. $\mathrm{CO}$ conversions with reaction temperature over $\mathrm{Au}-\mathrm{Ag} / \mathrm{SiO}{ }_{2}$ with varying $\mathrm{Au} / \mathrm{Ag}$ ratios. In each experiment, $60 \mathrm{mg}$ of the catalyst was used. (a) Gas mixture, $\mathrm{CO} / \mathrm{O}_{2} / \mathrm{He}=1 / 1 / 98$ (vol.); flow rate, $20 \mathrm{~mL} \mathrm{~min}^{-1}$. $\mathrm{Au} / \mathrm{TiO}_{2}$ is provided by the World Gold Council: $\mathrm{Au} / \mathrm{TiO}_{2}$-a was used as received and $\mathrm{Au} / \mathrm{TiO}_{2}$-b was calcined at $500{ }^{\circ} \mathrm{C}$ for $6 \mathrm{~h}$ followed by reducing in $\mathrm{H}_{2}$ at $550{ }^{\circ} \mathrm{C}$ for $1 \mathrm{~h}$. (b) Gas mixture, $\mathrm{CO} / \mathrm{O}_{2} / \mathrm{H}_{2} / \mathrm{He}=1 / 0.5 / 50 / 48.5$

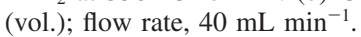

oxidation. As shown in Figure 8a, the $\mathrm{Au}-\mathrm{Ag}$ alloy catalysts are active for $\mathrm{CO}$ oxidation even at a reaction temperature as low as $-50^{\circ} \mathrm{C}$, and they all greatly outperform either of the monometallic ones. Table 2 lists the turnover frequencies (TOFs) of the catalysts, which are calculated based on the relationship between the particle size and the dispersion. ${ }^{60}$ It is found that the TOF of the $\mathrm{Au}-\mathrm{Ag} / \mathrm{SiO}_{2}(3 / 1)$ is nearly 5 times larger than that of the $\mathrm{Au} / \mathrm{SiO}_{2}$. The activities follow the order of $\mathrm{Au}-\mathrm{Ag}(3 / 1) / \mathrm{SiO}_{2}>\mathrm{Au}-\mathrm{Ag}(1 / 1) / \mathrm{SiO}_{2}>\mathrm{Au} /$ $\mathrm{TiO}_{2}>\mathrm{Au} / \mathrm{SiO}_{2} \gg \mathrm{Ag} / \mathrm{SiO}_{2}$. Compared with Au-organic$\mathrm{SiO}_{2}$ (the last row in Table 2), which was claimed to be as active as $\mathrm{Au} / \mathrm{TiO}_{2},{ }^{18}$ our $\mathrm{Au}-\mathrm{Ag} / \mathrm{SiO}_{2}$ catalysts exhibit a much higher reaction rate at a very short contact time, at least 1 order of magnitude shorter than that used for the goldorganic- $\mathrm{SiO}_{2}$ catalyst. To further show the superior sinteringresistant property of the $\mathrm{Au}-\mathrm{Ag}$ bimetallic system, we calcined $\mathrm{Au} / \mathrm{TiO}_{2}$ at $500{ }^{\circ} \mathrm{C}$ for $6 \mathrm{~h}$ and then reduced it in hydrogen at $550{ }^{\circ} \mathrm{C}$ for $1 \mathrm{~h}$. The activity test result showed that after such high-temperature treatment, the activity of the $\mathrm{Au} / \mathrm{TiO}_{2}$ was considerably decreased (as shown by $\mathrm{Au} /$

(60) Bond, G. C.; Thompson, D. T. Catal. Rev. Sci. Eng. 1999, 41, 319.
$\mathrm{TiO}_{2}$-b in Figure 8a), which is in contrast with our $\mathrm{Au}-\mathrm{Ag}$ / $\mathrm{SiO}_{2}$. It is also noted that, in spite of the comparable particle size, $\mathrm{Au}-\mathrm{Ag}(3 / 1)$ possesses a higher activity than $\mathrm{Au}-\mathrm{Ag}$ $(1 / 1)$. This implies that in addition to the particle size effect, there may be synergetic electronic effect between $\mathrm{Au}$ and $\mathrm{Ag}$ affecting the catalytic performance of $\mathrm{Au}-\mathrm{Ag}$ alloy. When using different supports (nano silica, alumina, SBA15), the $\mathrm{Au}-\mathrm{Ag}$ particles also exhibited a high catalytic activity for $\mathrm{CO}$ oxidation (Figure S8). In the case of excess $\mathrm{H}_{2}$ present in the reacting stream (so-called preferential oxidation of $\mathrm{CO}$ in $\mathrm{H}_{2}$ ), our $\mathrm{Au}-\mathrm{Ag}$ catalysts also show superior performances. As shown in Figure $8 b$, the CO conversion decreases with increasing the reaction temperature over all the gold-containing catalysts due to the competitive $\mathrm{H}_{2}$ oxidation. However, at room temperature, both the $\mathrm{CO}$ conversion and the selectivity to $\mathrm{CO}_{2}$ over the $\mathrm{Au}-\mathrm{Ag}(\mathrm{Au} /$ $\mathrm{Ag}=1 / 1$ ) catalyst are nearly $100 \%$. In comparison with our earlier reported $\mathrm{Au}-\mathrm{Ag} @ \mathrm{MCM}-41$ system, ${ }^{30}$ which was completely inactive for the preferential oxidation of $\mathrm{CO}$ under excess condition, the present $\mathrm{Au}-\mathrm{Ag}$ nanoparticles display exceptional performance with or without the presence of $\mathrm{H}_{2}$, reemphasizing the importance of the small particle sizes of the nanocatalysts.

\section{Conclusions}

In summary, we have developed a general strategy to obtain small-sized, thermally stable, and highly active $\mathrm{Au}-\mathrm{Ag}$ nanoparticles on commerically available silica and alumina supports. We believe this method can be extended to a variety of other supports with rich hydroxyl groups on their surfaces. The resultant nanostructure composed of $\mathrm{Au}-\mathrm{Ag}$ alloy core and a silver nanoshell can greatly limit the aggregation of nanoparticles during the high-temperature calcinations, thanks to the formation of a thin protective silver oxide layer that can act as a nanoglue between the silica substrate and the gold-silver particles. The final $\mathrm{H}_{2}$-reduction treatment not only reduced the thin oxide layer but also induced realloying of gold and silver, thereby activated the catalyst. Attributed to a remarkably decreased particle size and a possible promoting role of $\mathrm{Ag}$ in activating oxygen, thus-prepared gold-silver alloy particles give rise to excellent performance in catalyzing $\mathrm{CO}$ oxidation, even in a $\mathrm{H}_{2}$-rich atmosphere. This strategy of stabilizing the gold particles by alloying with a second metal paves a novel way for controlling the particle sizes and for enhancing the thermal stabilities of gold particles, in particular on those inert supports.

Acknowledgment. Support from the National Natural Science Foundation of China (NNSFC 20673116, 20773124, 20325620) (T.Z. and A.Wang), NKBRSF (2006CB932305), and NNSFC (20525104) (J.L.) are gratefully acknowledged.

Supporting Information Available: EDS spectra, TEM images, $\mathrm{N}_{2}$ sorption isotherms of different supports, XPS spectra, and activity profiles (PDF). This material is available free of charge via the Internet at http://pubs.acs.org.

\section{CM8027725}

